pint of a gruelly-looking fluid in the abdominal cavity. After searching in vain for a cause for the peritonitis we finally discovered a clean-cut perforation, about half an inch in diameter, in the posterior wall of the stomach, and in the centre of an ulcer three times as large. We afterwards learned that the woman had been a sufferer from dyspepsia for a long time.

The specimen is in the museum of the Boston Society for Medical Improvement.

\title{
A CASE OF FOREIGN BODY IN THE AIR-PASSAGES.
}

By G. D. Btevens, M. D., Gloucester.

ON August 14, 1876, Mrs. R., aged seventy-nine, after a dinner of baked beans, partaken of without inconvenience, took a small piece of cracker and a little tea. No sooner had an attempt been made at swallowing these than violent coughing and strangling followed, with the sensation of something passing down the right side of the throat and lodging in the chest beneath the right collar bone. After about fifteen minutes of great distress, vomiting took place with some relief, though severe coughing continued for more than two hours.

For the next five days there was a short, hacking cough, but no severe paroxysms. On the $19 \mathrm{th}$, immediately after rising, a very severe fit of coughing began, during which something was felt to rise towards the throat, producing for a few moments an intense feeling of suffocation.

I first saw the patient at noon of the 19th. The severity of the morning's symptoms had then abated. There was a frequent, short, dry cough, produced, according to her sensations, by "a tickling in the throat." The voice was unaffected. There was no localized pain, though complaint was made of soreness over the whole chest. A physical examination showed the lungs to be in an emphysematous condition from disease of long standing, but gave no clew to the situation of the foreign body.

For the next eight days the patient was kept as comfortable as possible by opiates in small doses, at varying intervals, to allay irritation, though cough at times was severe, with slight muco-purulent expectoration. There was no localized pain, but the same general soreness of the chest as before. Repeated physical examinations disclosed nothing as to the presence of the foreign substance. The pulse varied from 90 to 96. There were no chills or feverishness.

At five o'clock on the morning of the 27th, after an exceptionally comfortable night, in a paroxysm of coughing of greater severity than either preceding one, and so violent that to the attendants suffocation seemed imminent, a small cooked bean, in two fragments, was ejected, since which time all symptoms of irritation in the air-passages have rapidly declined. 